SANDIA REPORT

SAND94-0774 • UC-706

Unlimited Release

Printed May 1995

\title{
Prompt Laser Ignition and Transition to Detonation in a Secondary Explosive
}

Robert E. Setchell, Wayne M. Trott

\author{
Prepared by \\ Sandia National Laboratories \\ Albuquerque, New Mexico 87185 and Livermore, California 94550 \\ for the United States Department of Energy \\ under Contract DE-AC04-94AL85000
}

Approved for public release; distribution is unlimited. 
Issued by Sandia National Laboratories, operated for the United States Department of Energy by Sandia Corporation.

NOTICE: This report was prepared as an account of work sponsored by an agency of the United States Government. Neither the United States Government nor any agency thereof, nor any of their employees, nor any of their contractors, subcontractors, or their employees, makes any warranty, express or implied, or assumes any legal liability or responsibility for the accuracy, completeness, or usefulness of any information, apparatus, product, or process disclosed, or represents that its use would not infringe privately owned rights. Reference herein to any specific commercial product, process, or service by trade name, trademark, manufacturer, or otherwise, does not necessarily constitute or imply its endorsement, recommendation, or favoring by the United States Government, any agency thereof or any of their contractors or subcontractors. The views and opinions expressed herein do not necessarily state or reflect those of the United States Government, any agency thereof or any of their contractors.

Printed in the United States of America. This report has been reproduced directly from the best available copy.

Available to DOE and DOE contractors from

Office of Scientific and Technical Information

PO Box 62

Oak Ridge, TN 37831

Prices available from (615) 576-8401, FTS 626-8401

Available to the public from

National Technical Information Service

US Department of Commerce

5285 Port Royal Rd

Springfield, VA 22161

NTIS price codes

Printed copy: A03

Microfiche copy: A01 


\section{DISCLAIMER}

Portions of this document may be illegible in electronic image products. Images are produced from the best available original document. 
SAND94-0774

Distribution

Unlimited Release

Category UC-706

Printed May 1995

\title{
PROMPT LASER IGNITION AND TRANSITION TO DETONATION IN A SECONDARY EXPLOSIVE
}

\author{
Robert E. Setchell \\ Advanced Systems Technology Department \\ Wayne M. Trott \\ Energetic and Multiphase Processes Department \\ Sandia National Laboratories \\ Albuquerque, New Mexico, 87185
}

\begin{abstract}
A two-stage approach to achieving detonation in a secondary explosive was developed in previous studies in which ignition resulted from low-energy hot wires or from laser diodes. In the current study, this approach was examined in some detail for the case of ignition by a pulsed, solid-state (rod) laser. An initial series of experiments used $\mathrm{Nd} / \mathrm{glass}, \mathrm{Nd} / \mathrm{YAG}$, and Ti/sapphire lasers to investigate the ignition of graphite-doped HMX in highly confined optical fixtures that incorporated a fast piezoelectric pressure transducer. Experimental parameters included the laser power history and the explosive column length. The results of these experiments guided a second series of experiments in which the ignition column explosive was terminated by a thin rupture disc in contact with a transition column of low-density HMX or some other material. The transition column was terminated with a piezoelectric time-of-arrival detector for determining overall function times. Parameters investigated included different laser sources, rupture disc thicknesses, and the transition column explosive characteristics. Overall function times less than 50 microseconds were obtained, and trends established by the various parameter studies indicate that further reductions in function time can be achieved.
\end{abstract}




\section{Acknowledgments}

The authors would like to thank John A. Merson for his help in planning the experiments, selecting the explosive powders used in this study, and for overseeing the assembly of the test fixtures. F. J. Salas assisted in these activities. Jaime N. Castaneda provided valuable assistance in overcoming Nd/glass laser problems and in conducting the numerous experiments. Dante $\mathrm{M}$. Berry was very helpful in tuning the Nd/YAG laser and in the initial setup and troubleshooting of the Ti/sapphire laser. Edward A. James provided valuable help in data acquisition and analysis.

\section{Preface}

This work was supported by Lab Directed Research and Development funding. The Appendix lists reporting information required by that funding source. This document was previously published under the same title in: Proceedings of the Fifteenth Symposium on Explosives and Pyrotechnics, Franklin Applied Physics, Oaks, Pennsylvania, 1994. 


\section{Contents}

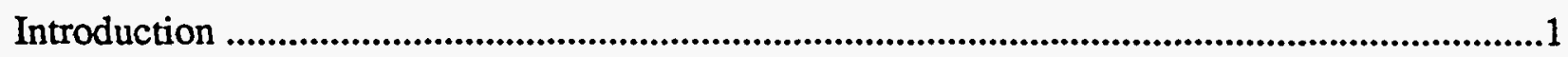

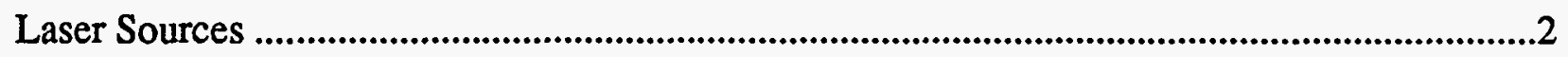

Ignition Stage Experiments .....................................................................................................4

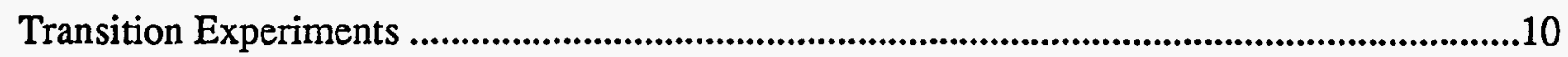

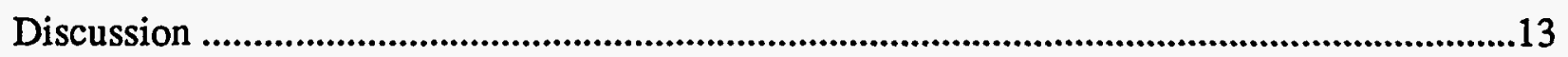

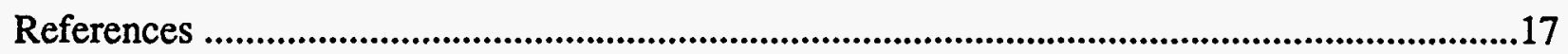

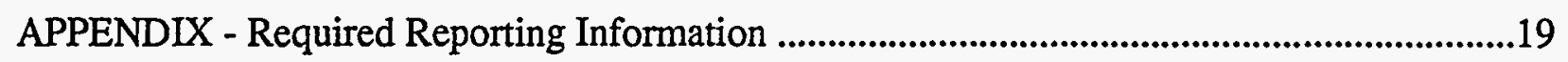

Figures

1. The two-stage approach for achieving detonation in a secondary explosive .............................1

2a. One operating condition of a custom Nd/Glass laser from Laser Photonics ..............................3

2b. A second operating condition of the custom Nd/Glass laser ........................................................

2c. Nominal operating characteristics of a Laser Photonics Nd/YAG laser ......................................3

2d. Nominal operating characteristics of a prototype Ti/sapphire laser from Cynosure ..................4

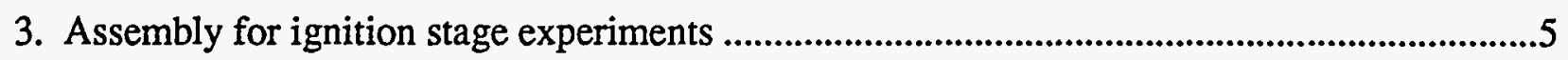

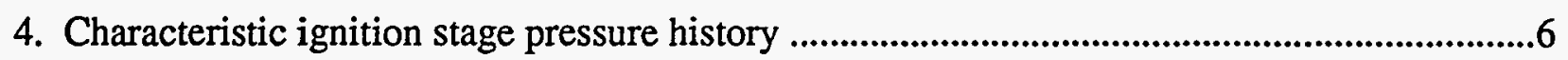

5. Initial pressure rise in ignition stage experiments .................................................................

6. Summary of "induction time" data ....................................................................................

7. Correlation between "induction times" and the delivered energy after $0.5 \mu \mathrm{s}$............................8

8. Complete ignition stage pressure histories .........................................................................

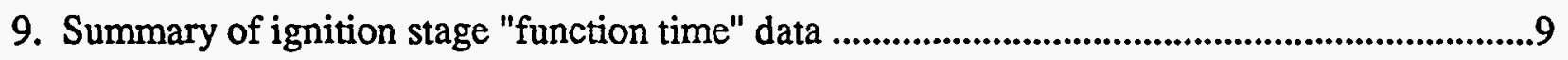

10. Assembly for complete transition experiments ...................................................................10 


\section{Figures - continued}

11. Estimates of rupture disc failure time 11

12. Delivered energy histories for three transition experiments ....................................................12

13. Post-test examination of transition column holders ..........................................................13

14. Post-test diameter measurements of transition column holders .............................................14

\section{Tables}

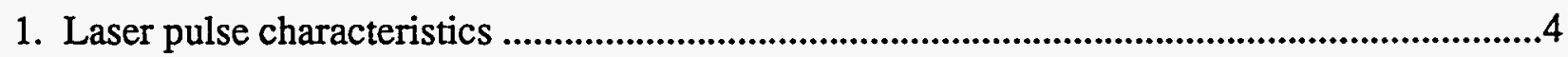

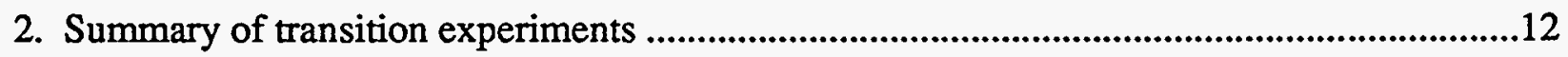




\section{Introduction}

Research into the response of explosives to laser irradiation spans a period of nearly thirty years, with investigators utilizing a variety of laser types and a broad range of high explosives and pyrotechnics. A practical motivation for these studies has been the development of explosive devices that are immune to accidental firing by unintended electrical signals. A convenient means for delivering laser outputs to such devices was provided when optical fibers having very low losses became available. A number of the past studies examined the generation of detonation waves in secondary explosives ${ }^{1}$. Very prompt laser initiation (i.e., excess transit times less than a microsecond) was achieved in several secondary explosives by generating shock waves using Q-switched, solid-state (rod) lasers 2,3. However, practical implementation of these results has been hindered by the relative complexity of the laser systems and the tendency of optical fibers to damage when transmitting the very high power densities necessary 4 .

A two-stage approach for achieving detonation after laser ignition at much lower power densities has been pursued recently by several investigators 5,6 . This approach involves segmenting the explosive device into separate ignition and transition stages, and is based on earlier development of deflagration-to-detonation devices that utilized hot-wire ignition 7,8 . The basic elements of an optical two-stage device are shown in Fig. 1. The

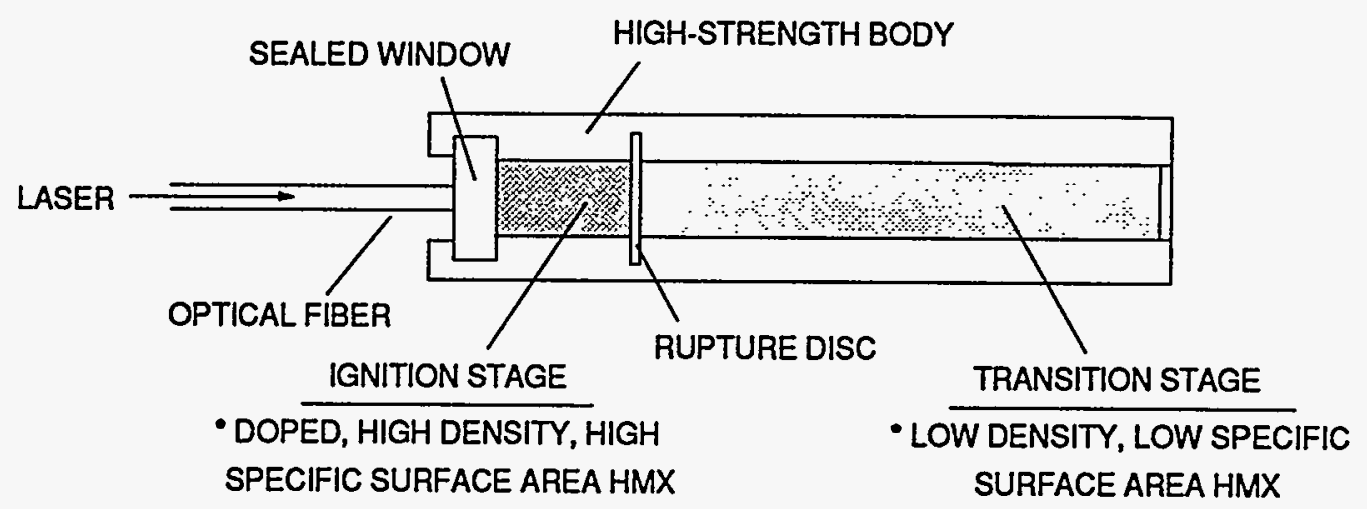

Fig. 1. The two-stage approach for achieving detonation in a secondary explosive.

ignition stage is confined on one end by a sealed window, and on the other end by a rupture disc. Laser absorption in the ignition stage explosive results in confined burning up to a pressure dictated by the rupture disc. Subsequent rupturing of this disc results in rapid compression in the transition stage, where shock formation and transition to detonation occur. The explosive properties in the two stages are tailored to facilitate their different roles. The ignition stage explosive can be doped with a few percent of carbon black or graphite to improve its optical absorption at the laser wavelength ${ }^{9}$. Most of the reported work has used HMX in both stages and ignition by laser diodes, although HMX ignition by solid-state lasers has also been mentioned. Reported function times for devices ignited by laser diodes have been as short as 0.4 milliseconds 5 . In the current study this two-stage approach to achieving detonation in a secondary explosive using solid-state laser ignition has been examined in some detail. 
The basic objective of the present work was to examine the extent to which overall function times could be reduced in a secondary-only, two-stage optical device that did not require firing by a $\mathrm{Q}$-switched laser. This goal was pursued through experimental studies of variables that influence time scales for ignition, growth of reaction, shock formation, and transition to detonation. An initial series of experiments utilized fixtures that consisted only of an ignition stage terminated by a fast-response piezoelectric pressure transducer. Using pulsed (non Q-switched) Nd/Glass, Nd/YAG, and Ti/sapphire lasers to vary the incident optical power history, the growth of pressure in graphite-doped HMX ignition stages of various lengths was recorded in time. Results were used to guide a second series of experiments utilizing fixtures in which the pressure transducer was replaced with a titanium-alloy rupture disc having variable thickness followed by a transition column of HMX or some other material. Shock or detonation wave breakout was recorded using a piezoelectric element at the end of the transition column. Transition fixtures were subsequently sectioned to observe the change in transition column diameter with length. Overall function times less than 50 microseconds were achieved, and the trends established by the various parameter studies indicate that further reductions in function time can be realized. The next section provides details on the different laser sources used in the current study. The following section describes the ignition stage experiments, and summarizes their results. Complete transition experiments and their results are then described. The final section discusses the results and summarizes the established trends.

\section{Laser Sources}

The effects of laser power history on ignition and subsequent reaction growth were of particular interest in the current study. A number of laser types were used to vary this power history over a broad range. All lasers were flashlamp-pumped, solid-state (rod) lasers operating at their fundamental wavelength in a free-running (non Q-switched) pulsed mode. A custom Nd/Glass laser from Laser Photonics with adjustable parameters in its flashlamp firing circuit was used to provide two types of input conditions. A Laser Photonics Model YNL-102 Nd/YAG laser was used with full or attenuated output to provide other input conditions. The output of both of these lasers consisted primarily of an extended sequence of relaxation oscillation "spikes," with little output power between the spikes. A prototype Ti/sapphire laser that not only used flashlamp pumping but also solid-state pump conversion (rather than conversion by liquid dyes) was provided by Cynosure, and resulted in more energy deposition earlier in time than could be obtained with the other lasers. In addition to having a much shorter overall pulse duration, the $\mathrm{Ti} /$ sapphire laser output consisted of smaller high-frequency spikes superimposed on a broader high-amplitude profile. Figs. 2a-2d show the output power histories of these lasers during the first twenty microseconds of their pulses. The incident power values correspond to conditions arriving at the HMX/window interface in the ignition stage after transmission through an optical fiber. Also shown in these figures are "delivered" energies as a function of time. The energy curves are simply the time integrals of the incident power curves, and do not account for reflected and scattered light that is not ultimately absorbed by the doped explosive. The Nd/Glass laser (Figs. 2a and 2b) has relaxation 


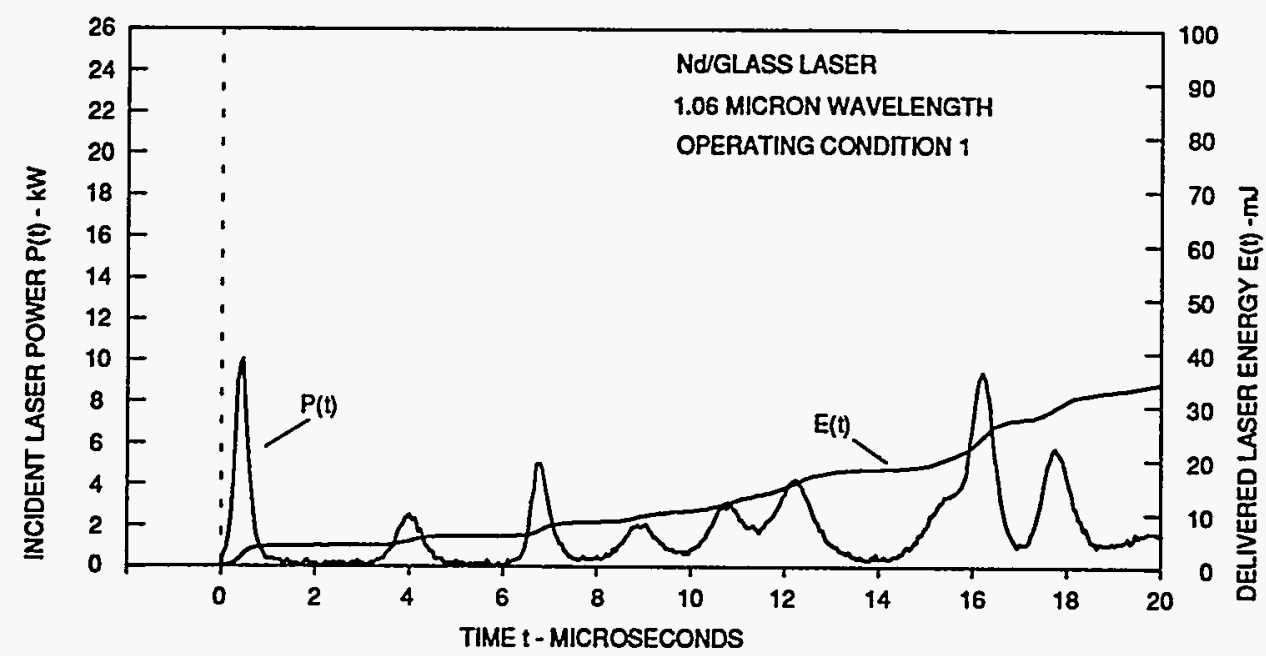

Fig. 2a. One operating condition of a custom Nd/Glass laser from Laser Photonics.

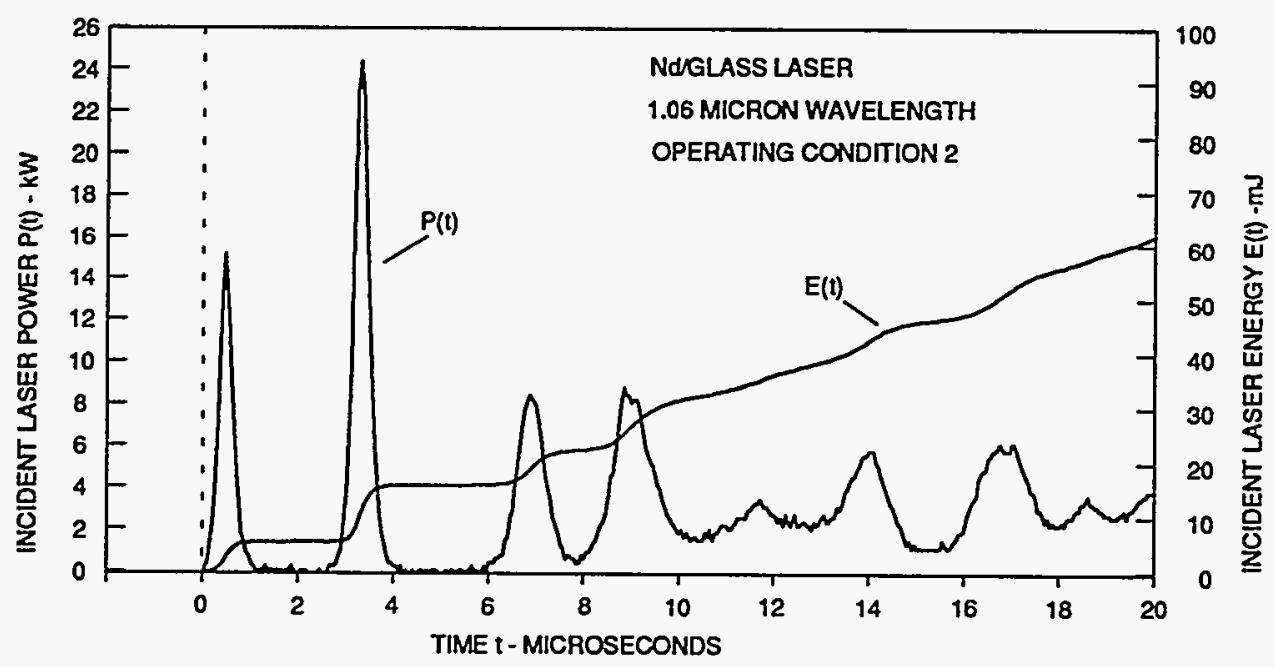

Fig. 2b. A second operating condition of the custom Nd/Glass laser.

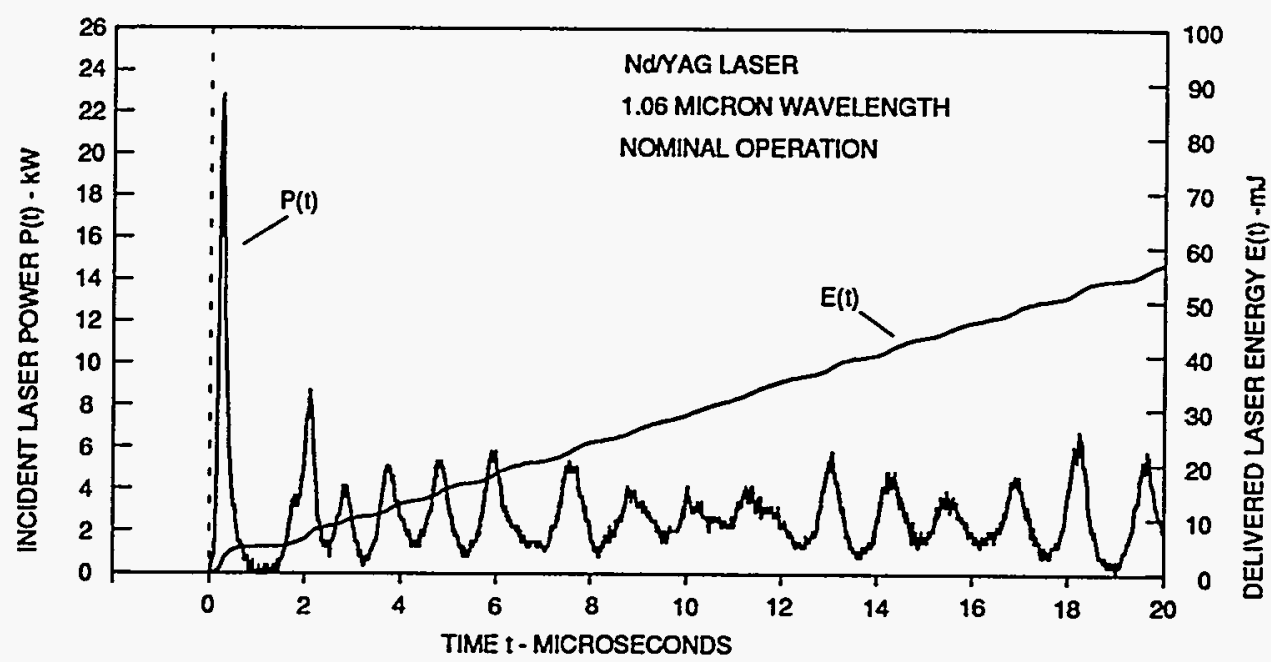

Fig. 2c. Nominal operating characteristics of a Laser Photonics Nd/YAG laser. 


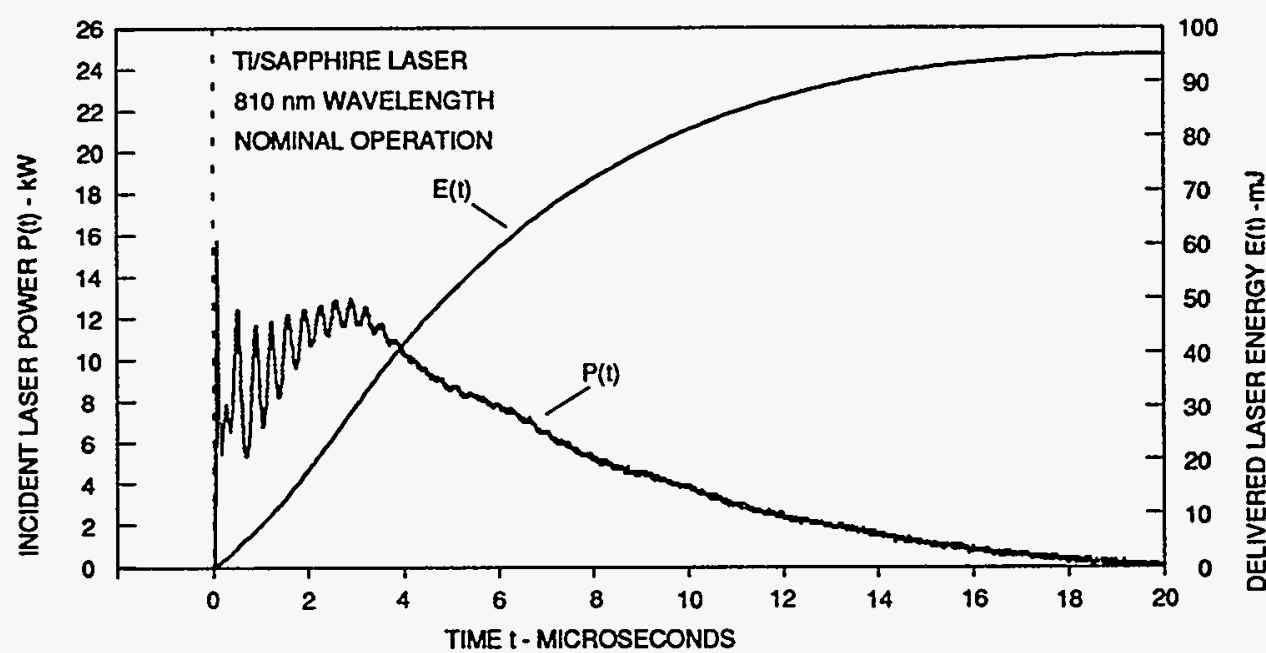

Fig. 2d. Nominal operating characteristics of a prototype Ti/sapphire laser from Cynosure.

oscillations occurring every $2-4 \mu$ s over a total pulse duration of hundreds of microseconds. The Nd/YAG laser has oscillations occurring every 1-2 $\mu$ s during a total pulse duration of less than $100 \mu \mathrm{s}$. The amplitudes of the individual oscillations from both of these lasers varied considerably during successive pulses, even though the total pulse energies would vary by only a few percent. The details of the Ti/sapphire laser output power history (Fig. 2d) were considerably more repeatable than those of the other lasers, with profiles from successive pulses essentially overlaying each other. Table 1 gives additional information on nominal delivered energies at different times during each laser's output, as well as some characteristic pulsewidths.

TABLE 1. Laser Pulse Characteristics

\begin{tabular}{|c|c|c|c|c|c|c|c|c|}
\hline \multirow{2}{*}{ LASER } & OPERATING & \multicolumn{5}{|c|}{ DELIVERED ENERGY - $\mathrm{mJ}$} & \multicolumn{2}{c|}{ PULSEWIDTH $-\mu \mathrm{s}$} \\
& CONDITION & $E(5 \mu \mathrm{s})$ & $E(10 \mu \mathrm{s})$ & $\mathrm{E}(20 \mu \mathrm{s})$ & $\mathrm{E}(40 \mu \mathrm{s})$ & $\mathrm{E}$-final & $\mathrm{t}_{1}$ & $\mathrm{t}_{2}$ \\
\hline Nd/GLASS & 1 & 6.9 & 10.5 & 34.2 & 110 & 502 & 81.2 & 210 \\
\hline Nd/GLASS & 2 & 15.0 & 31.7 & 62.1 & 132 & 942 & 118 & 331 \\
\hline NdYYAG & NOMINAL & 15.1 & 29.2 & 56.9 & 95.4 & 122 & 21.8 & 62.5 \\
\hline TUSAPPHIRE & NOMINAL & 54.8 & 81.2 & 95.0 & 95.0 & 95.0 & 4.60 & 13.4 \\
\hline
\end{tabular}

\section{Ignition Stage Experiments}

The experimental assembly used to examine ignition stage characteristics is shown in Fig. 3. A laser pulse was delivered to the ignition stage explosive through a step-index, fused silica fiber terminated with a standard SMA 906 connector. Most experiments were conducted using fibers having a core diameter of $0.40 \mathrm{~mm}$, but diameters of 0.20 and 1.0 $\mathrm{mm}$ were also used to examine the effects of laser spot size. The fiber end face contacted 


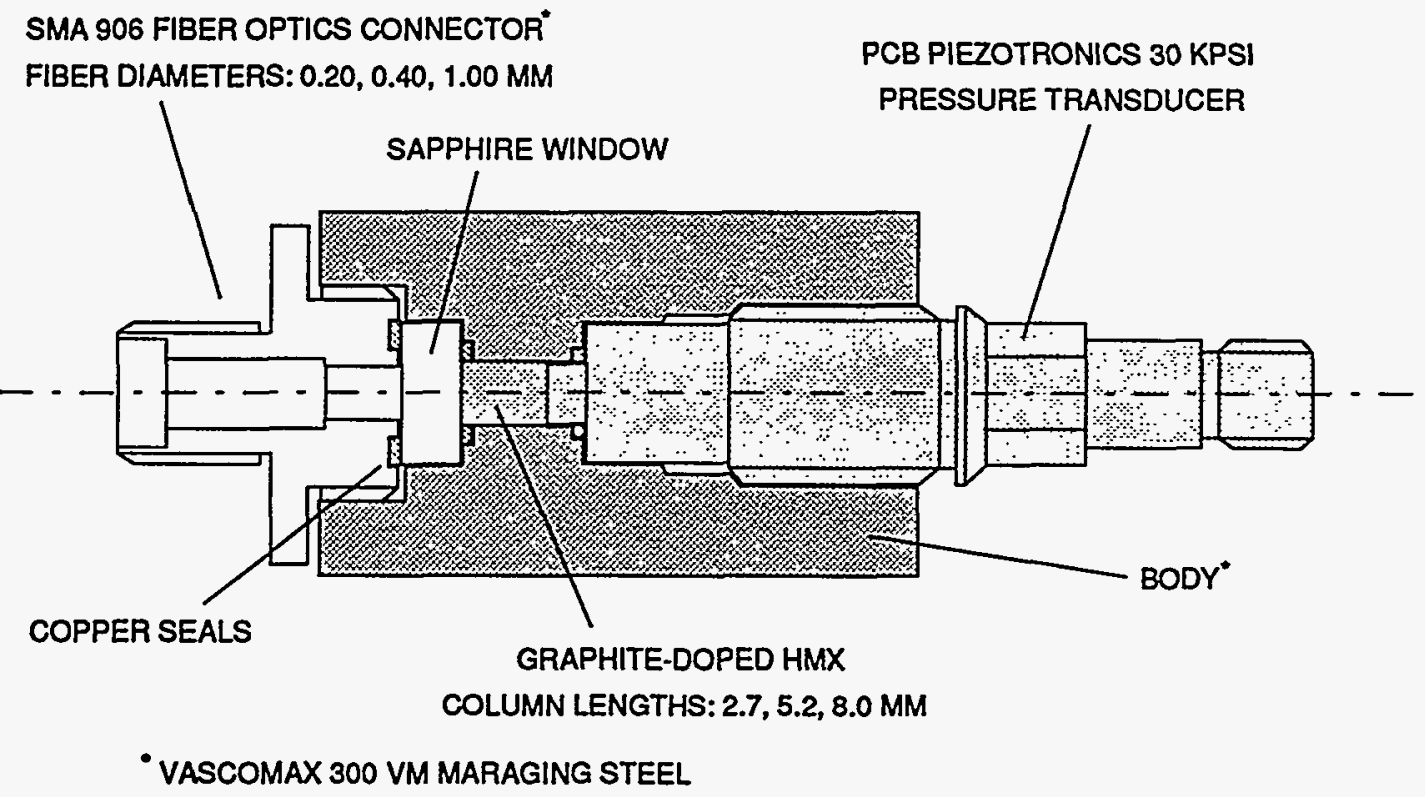

Fig. 3. Assembly for ignition stage experiments.

the $2.5-\mathrm{mm}$ thick sapphire window within the assembly. The ignition explosive used in all experiments was based on the work of Ewick ${ }^{5,9}$. HMX powder with a specific surface area of $7460 \mathrm{~cm}^{2} / \mathrm{g}$ was blended with $3 \%$ by weight graphite, then pressed to a density of $1.65 \mathrm{~g} / \mathrm{cm}^{3}$. The ignition column had a diameter of $2.5 \mathrm{~mm}$, and a length of $2.7 \mathrm{~mm}, 5.2$ $\mathrm{mm}$, or $8.0 \mathrm{~mm}$. A commercial piezoelectric transducer (PCB Piezotronics Model 105A43) was mounted on the opposite side of the ignition stage explosive. This model transducer has a specified linear range of $30,000 \mathrm{psi}$ and a rise time of $2 \mu \mathrm{s}$. To provide the necessary pressure confinement for the laser-ignited $\mathrm{HMX}$, static copper seals on both the window and pressure transducer were compressed to a stress beyond their elastic yield strength. No assembly parts were used for more than a single experiment.

In each experiment, a calibrated fraction of the laser output was directed to both a fast phototube and an energy meter. The phototube signal was recorded simultaneously with the pressure transducer output on a digitizing oscilloscope (Tektronix Model 602 DSA). The phototube signal was proportional to instantaneous laser power, and the proportionality constant was determined from the energy measurement and by subsequent signal integration. The actual pressure values were found from recorded transducer outputs using the manufacturer's calibration for each unit. A typical pressure history is shown in Fig. 4. Zero time in this figure and in subsequent figures corresponds to the start of measurable laser output. Several distinct segments are identified in the figure. The initial period labeled "induction time" corresponds to the time for which there is no observable rise in pressure. This time is actually a combination of the time from the start of laser output to the start of pressure generation due to reaction in the initial volume of laser-heated HMX (adjacent to the window), a transit time for wave motion to reach the piezoelectric transducer, and the transducer response time. This period is followed by a fairly rapid pressure rise up to a level of a few thousand psi. The next segment is an extended period of slow pressure growth, followed by a rapid rise to levels beyond the 


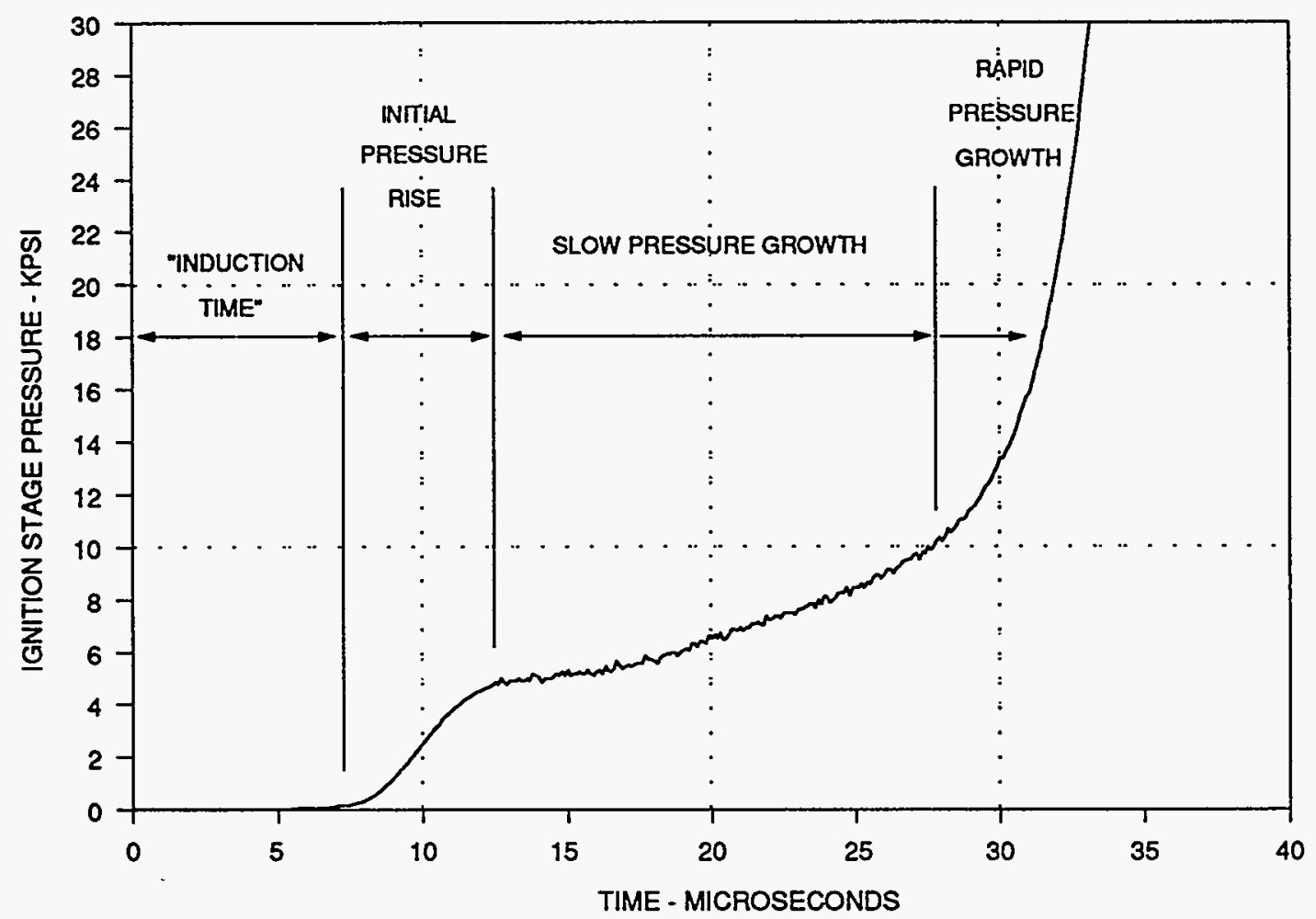

Fig. 4. Characteristic ignition stage pressure history.

linear range of the transducer. Although most pressure histories showed all of the features identified in Fig. 4, the details of these features varied widely. The experimental parameters that were altered in different experiments (laser source, explosive column length, and spot size at the window/HMX interface) all had significant effects. In addition, there was substantial variability between experiments in which the parameters were not changed. The causes for this variability will be discussed in a subsequent section.

Figure 5 shows the initial pressure rise observed in a few experiments in which the laser source and explosive column length were varied. An arbitrary measure of the initial "induction time" can be identified as the time required to reach a pressure of $300 \mathrm{psi}$ (a value above the level of initial oscillations that could be due to wave motion in the assembly structure). Using this measure, Fig. 6 shows a broader range of experimental results. For each column length, the Ti/sapphire laser consistently gave the fastest times, and the Nd/glass laser cases gave the slowest. Times increased with increasing fiber diameter (corresponding to decreasing power/energy density). The line shown in this figure approximates the fastest results (Ti/sapphire laser), and has a slope corresponding to a wave speed of $1 \mathrm{~km} / \mathrm{s}$. This line extrapolates back to the origin, indicating that the time from the start of laser output to the start of pressure generation in the initial volume of HMX heated by the laser is very short. Efforts to correlate this measure of "induction time" with details of the laser power histories (for a fixed column length) were largely unsuccessful. Even though the energy content and timing of the initial relaxation oscillation "spikes" from the YAG and glass lasers (Figs. 2a-2c) varied considerably, the power $P(t)$ and deposited energy $E(t)$ histories were determined for every experiment. 


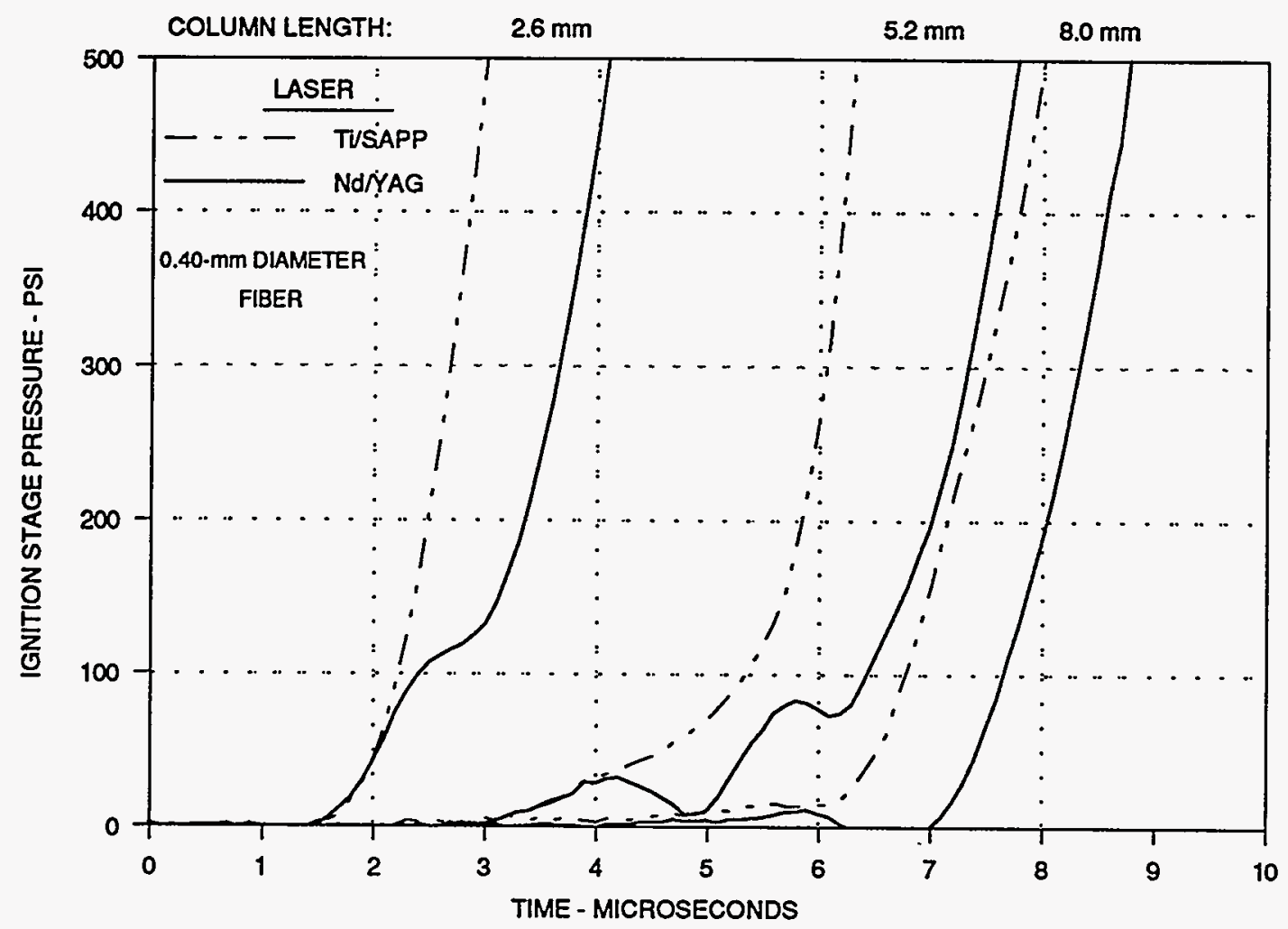

Fig. 5. Initial pressure rise in ignition stage experiments.

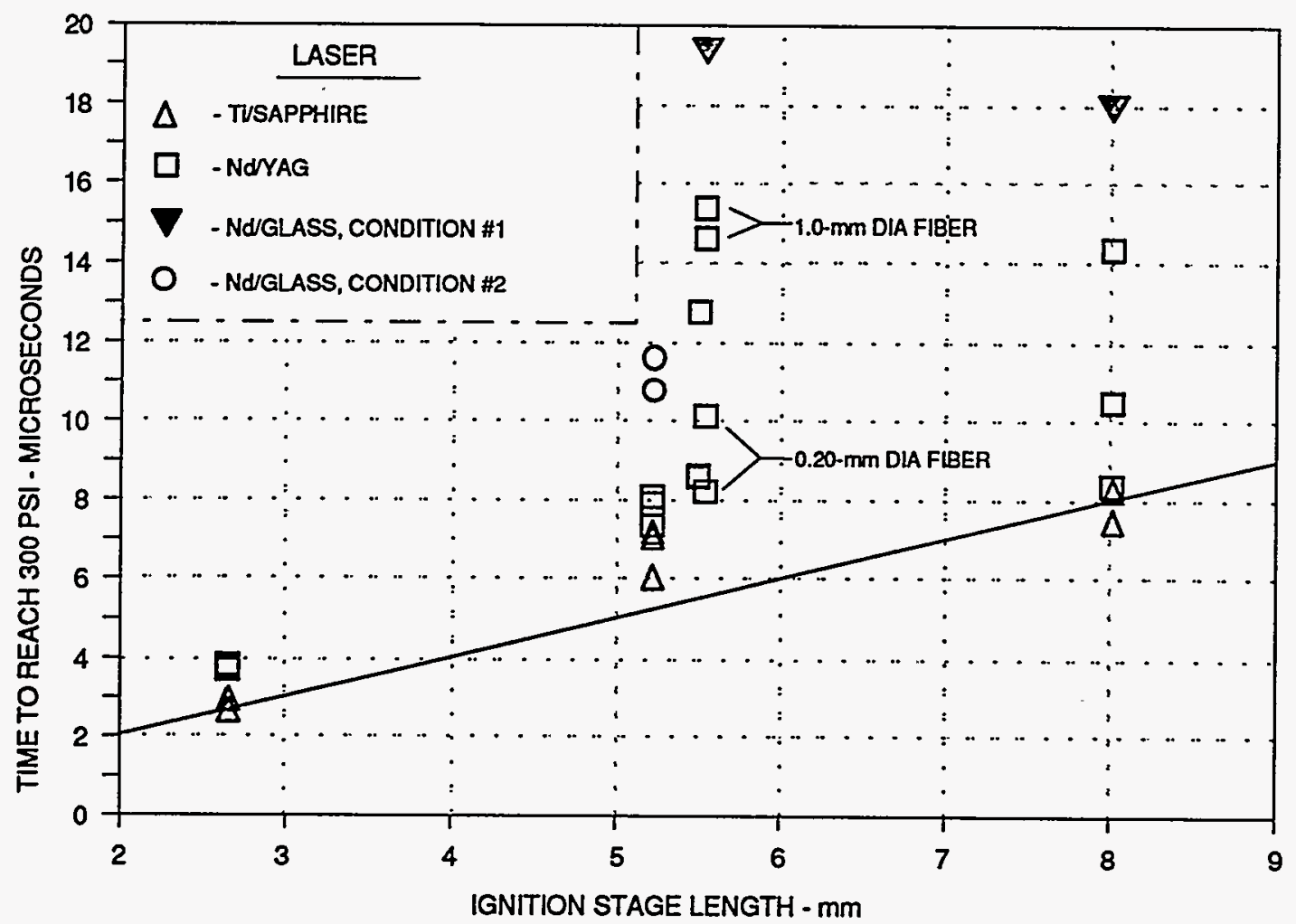

Fig. 6. Summary of "induction time" data. 
Correlations based on deposited energy after some number of spikes, or peak power of the first one or two spikes, always resulted in inconsistencies. The most consistent correlation obtained is shown in Fig. 7, in which "induction time" is plotted versus the delivered energy at a time of $0.5 \mu \mathrm{s}$. This figure shows the data obtained for all laser sources using a column length of $8.0 \mathrm{~mm}$, including results obtained by attenuating the $\mathrm{Nd} / \mathrm{YAG}$ laser output by factors of 3 and 10 .

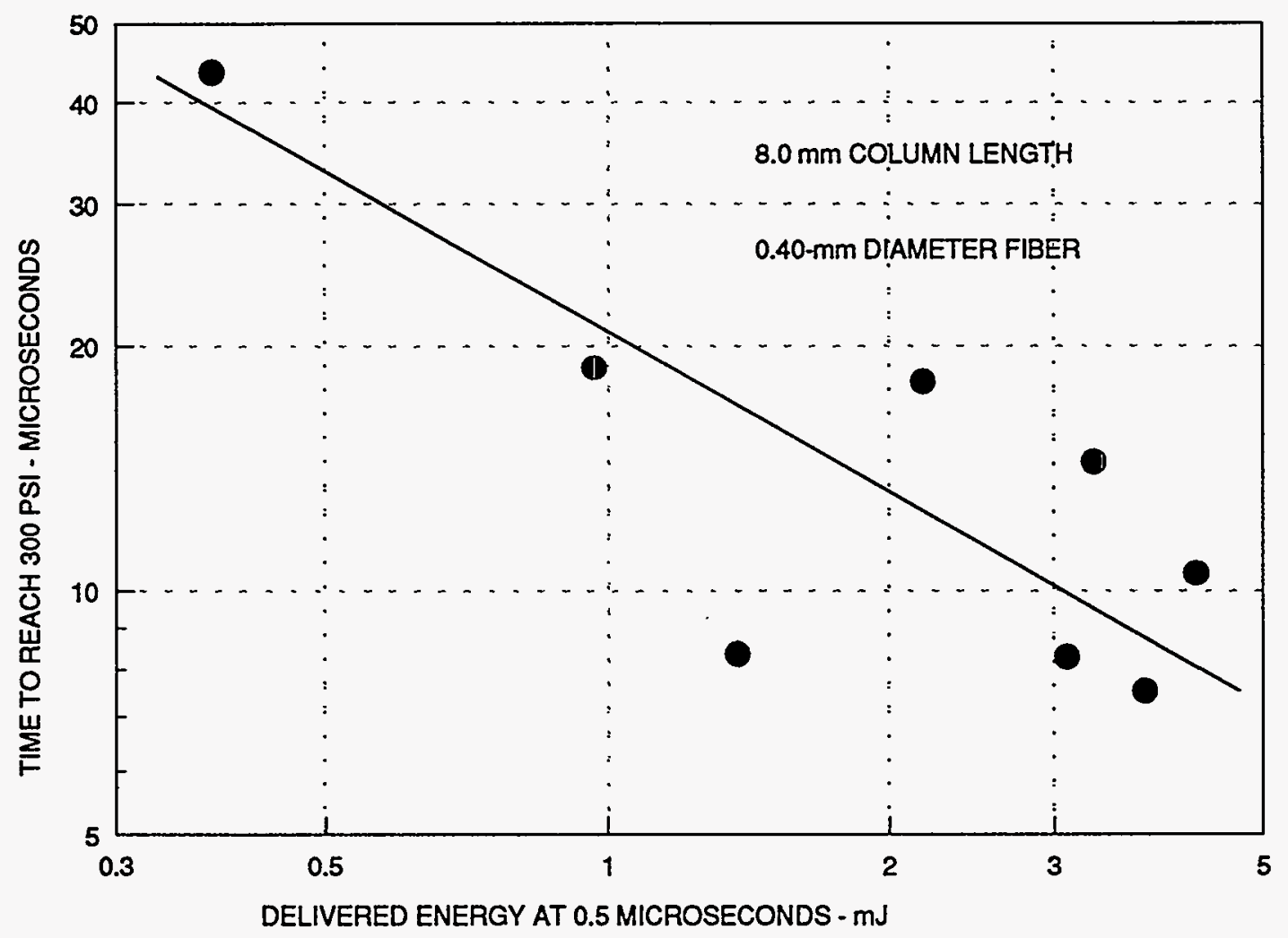

Fig. 7. Correlation between "induction times" and the delivered energy after $0.5 \mu \mathrm{s}$.

Figure 8 shows a few complete pressure histories recorded up to the limit of the transducer's linear range. Results obtained for the shortest column length have a very fast initial pressure rise and essentially no period of slow pressure growth. Results for the longest column length have the longest period of slow pressure growth. As shown in one of these curves, the final pressure rise was not always smoothly accelerating. One measure of the ignition stage "function time" that can be drawn from these measurements is the time required for the pressure to reach $30 \mathrm{kpsi}$. For a complete transition device having a rupture disc intended to fail at a pressure near $30 \mathrm{kpsi}$, this measure indicates the time required from the onset of laser output until disc rupture. Figure 9 displays a summary of this ignition stage "function time" data for a broad range of experimental conditions. As in the initial pressure rise data shown in Fig. 6, considerable variability exists even for cases where experimental parameters were held fixed. A trend for increasing times with increasing column length is apparent, but trends based on laser source or spot size are not evident. 


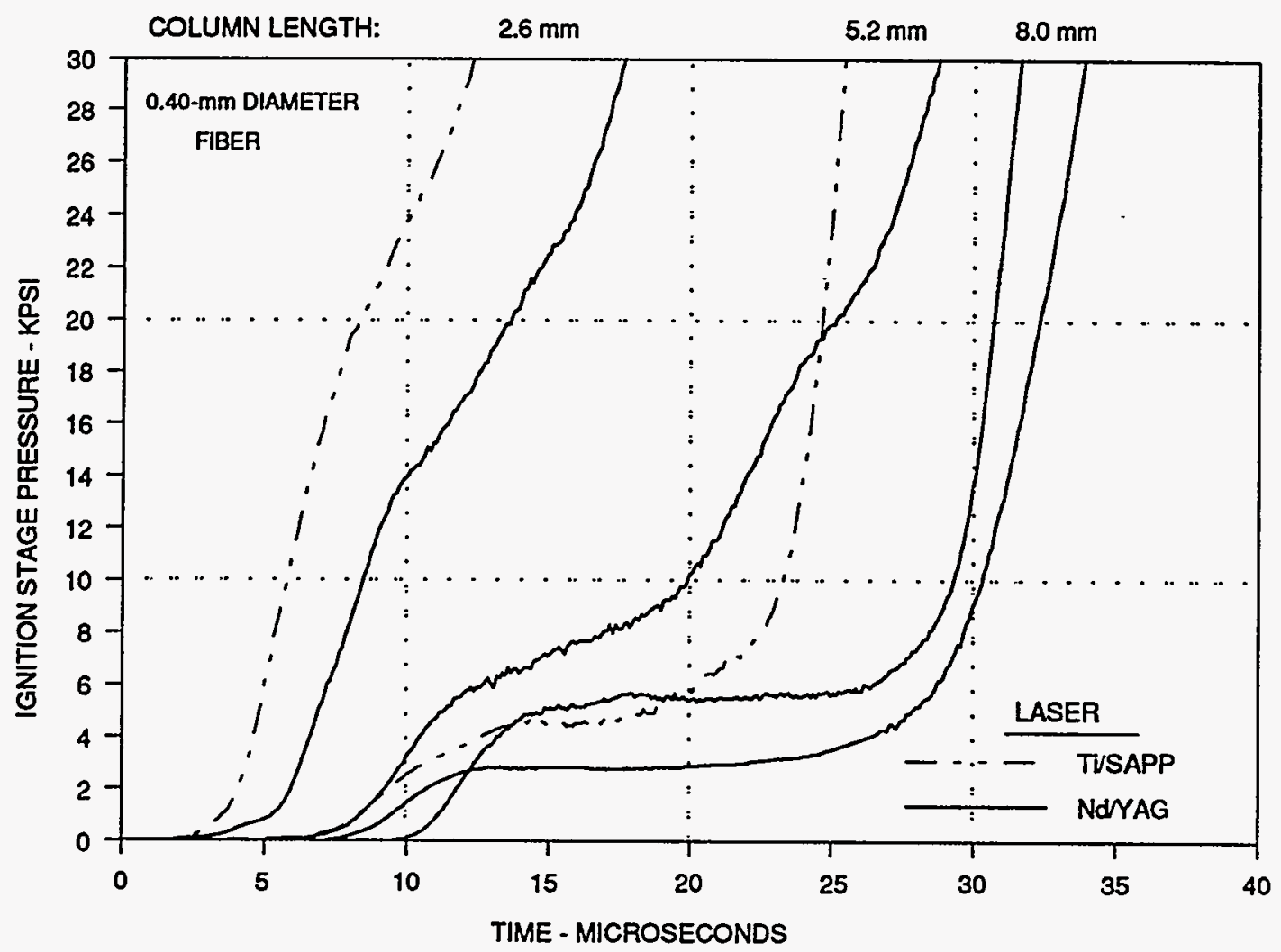

Fig. 8. Complete ignition stage pressure histories.

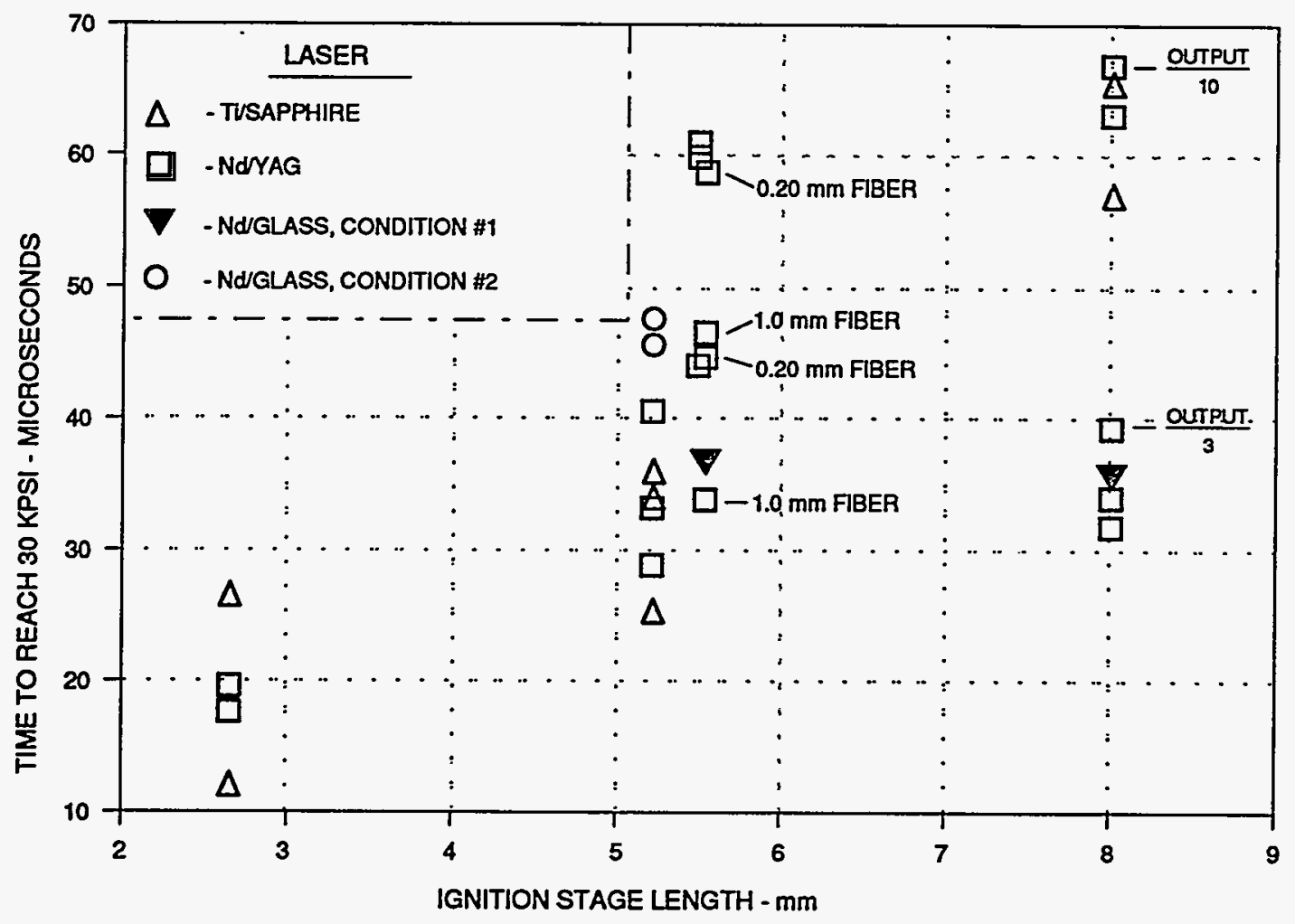

Fig. 9. Summary of ignition stage "function time" data. 


\section{Transition Experiments}

The two-stage assembly used to investigate transition to detonation is shown in Fig. 10. A titanium alloy (Ti-6Al-4V) rupture disc having variable thickness is located at the end of the ignition stage explosive column. The ignition stage explosive was the same as in previous experiments. The $2.5-\mathrm{mm}$ diameter transition column was typically loaded with low-density HMX powder having either a fine or coarse grain size. A number of initial experiments used an inert material $(\mathrm{NaCl})$ in the transition column in order to observe rupture disc failure times, and a few experiments were conducted with low-density PETN as the transition explosive. The transition column was $16.5 \mathrm{~mm}$ long and sealed with a piezoelectric time-of-arrival detector for determining overall function times. The end of the threaded transition column holder had two shallow holes to permit assembly using a spanner wrench. The ignition stage column length was fixed at $8.0 \mathrm{~mm}$ in all transition experiments. Although this length resulted in longer times to achieve maximum pressures (Fig. 9), the larger mass of ignition explosive was considered more likely to drive the sheared rupture disc into the transition explosive effectively. In addition, only the $\mathrm{Nd} / \mathrm{YAG}$ and the Ti/sapphire lasers were used. As in the ignition stage experiments, a calibrated portion of the laser output was directed into both an energy meter and a phototube detector. The digitizing oscilloscope was used to record both the phototube signal and the output from the piezoelectric element at the end of the transition column.

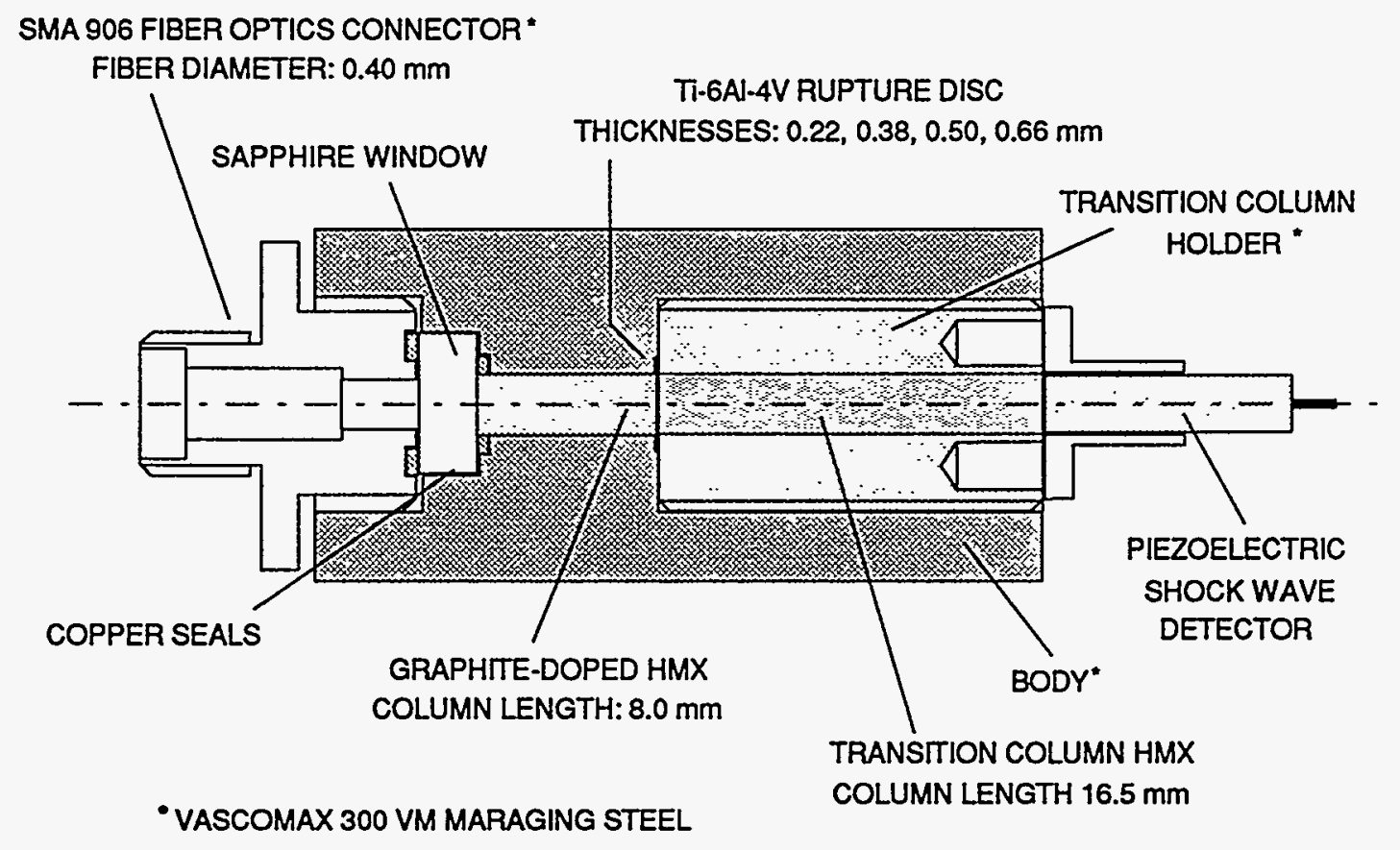

Fig. 10. Assembly for complete transition experiments.

An initial series of experiments using the assembly in Fig. 10 had only a 6-mm length of powdered $\mathrm{NaCl}$ loaded to a density of approximately $1.0 \mathrm{~g} / \mathrm{cm}^{3}$ within the transition column. The piezoelectric time-of-arrival detector was inserted into the transition column holder for these tests. Different thickness rupture discs were used, and the resulting detector signals provided the corresponding times when compressive waves driven by the 
rupture disc motion reached the end of the $\mathrm{NaCl}$ powder. A value for the sound speed in this material 10 was then used to estimate the time for the onset of disc motion. Figure 11. shows the results of these experiments, along with additional estimates obtained in subsequent experiments that used an explosive in the transition column. The ranges shown in this figure correspond to three to five estimates for each value of rupture disc thickness. The fastest values for disc failure times indicate the expected increase with increasing disc thickness, although the typical scatter in values for each thickness is quite large.

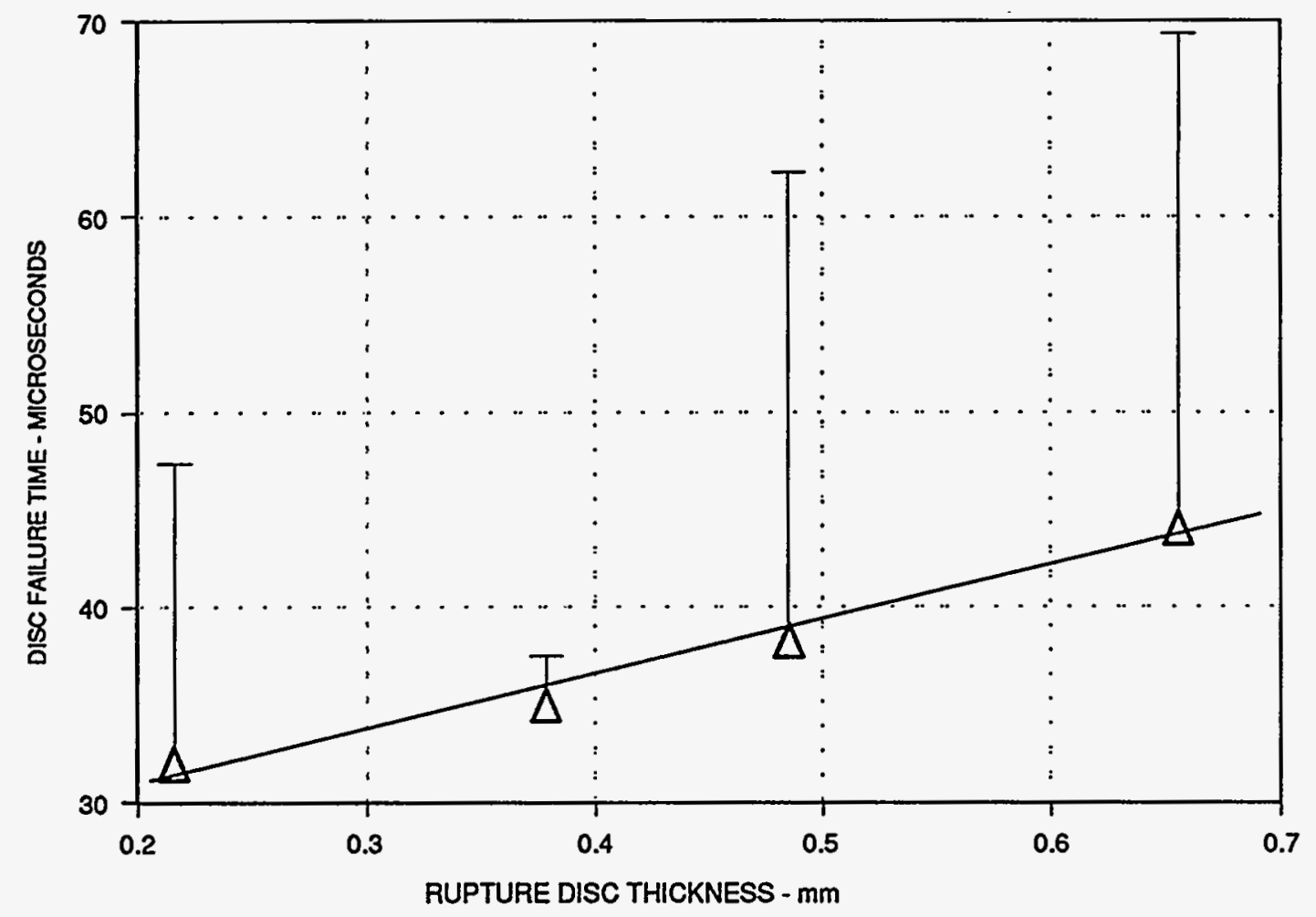

Fig. 11. Estimates of rupture disc failure time.

Two types of HMX powders were used in complete transition experiments. The first was a fine powder for which Microtrac particle size measurements ${ }^{11}$ gave a mean diameter of 12 microns and an overall range of diameters from 2 to 40 microns. Fixtures having this material loaded to a density of $1.24 \mathrm{~g} / \mathrm{cm}^{3}$ and rupture disc thicknesses of 0.22 , 0.50 , and $0.66 \mathrm{~mm}$ failed to detonate when fired using the Nd/YAG laser. All of the explosive apparently burned, but the transition column holders showed no evidence of growth towards detonation (discussed below). As a very fine powder pressed to this density was expected to be difficult to detonate 7 , no further experiments with this material were performed. The second HMX powder was much coarser, having an average particle size of 150-200 microns and a diameter range from 50 to 350 microns ${ }^{12}$. Transition column holders were loaded with this material to a density of $1.16 \mathrm{~g} / \mathrm{cm}^{3}$. With one exception, every transition experiment conducted with this material produced significant expansion in the transition column holder, which was viewed as evidence that transition to detonation had occurred. A summary of these experiments is presented in Table 2. 
TABLE 2. Summary of Transition Experiments

\begin{tabular}{|c|c|c|c|c|}
\hline EXPERIMENT & LASER & $\begin{array}{l}\text { RUPTURE DISC } \\
\text { THICKNESS - mm } \\
\end{array}$ & $\begin{array}{c}\text { TRANSITION } \\
\text { COLUMN EXPLOSIVE } \\
\end{array}$ & $\begin{array}{l}\text { FUNCTION } \\
\text { TIME }-\mu s\end{array}$ \\
\hline $\mathrm{T} 1$ & TUSAPPHIRE & 0.38 & $H M X$ & 45.2 \\
\hline T2 & NAYAG & 0.38 & HMX & 45.6 \\
\hline T3 & NoYYAG & 0.50 & $H M X$ & 52.0 \\
\hline T4 & TVSAPPHIRE* & 0.50 & HMX & $\begin{array}{c}\text { DID NOT } \\
\text { DETONATE* }\end{array}$ \\
\hline T5 & NDYAG & 0.50 & PETN & 56.8 \\
\hline T6 & NOYAG & 0.66 & PETN & 63.4 \\
\hline $\mathrm{T7}$ & TISAPPHIRE & 0.66 & HMX & 65.4 \\
\hline T8 & NOYAG & 0.66 & $H M X$ & 110.4 \\
\hline
\end{tabular}

-LASER MISFIRE (LOW OUTPUT ENERGY)

Table 2 includes the results of two experiments in which the transition column holder was loaded with PETN powder to a density of $1.00 \mathrm{~g} / \mathrm{cm}^{3}$. A BET measurement of the specific surface area of this powder gave a value of $4000 \mathrm{~cm}^{2} / \mathrm{g}$. The experiment labeled "T4" involved a misfire of the Ti/sapphire laser, in which a fraction of the normal laser output was delivered to the ignition stage. Figure 12 shows the energy delivery histories for this experiment and for successful experiments using the two lasers. The misfire case delivered more energy than a successful case (T1) up to a time of $25 \mu \mathrm{s}$, yet this was insufficient to achieve detonation.

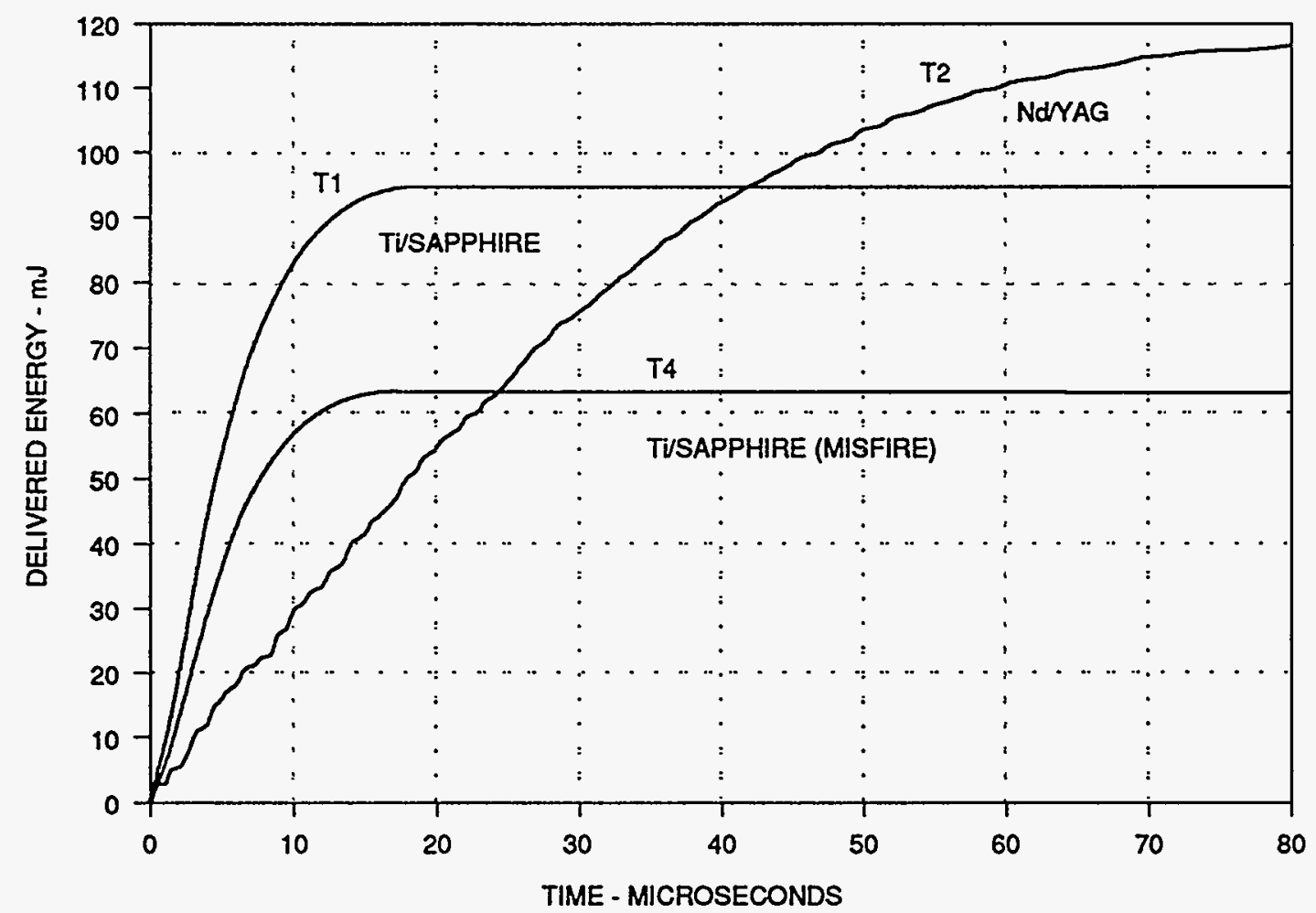

Fig. 12. Delivered energy histories for three transition experiments. 
After the transition experiments were completed, all fixtures were bisected along a symmetry axis using a low-speed diamond wheel saw. The exposed interiors showed an expansion in the diameter of the transition column holder, as sketched in Fig. 13. Each part was photographed, and diameter measurements as a function of distance were made from the photographs. Figure 14 shows these measurements up to the position where the spanner wrench holes begin. The thin wall beyond this position that divided the final portion of the transition column and the spanner wrench holes was missing in all fixtures that detonated (as indicated in Fig. 13). The case involving a laser misfire showed no transition column expansion except for a slight buckling of the thin walls adjacent to the spanner wrench holes. The fixtures containing the very fine-grained HMX showed no wall deformation whatsoever.

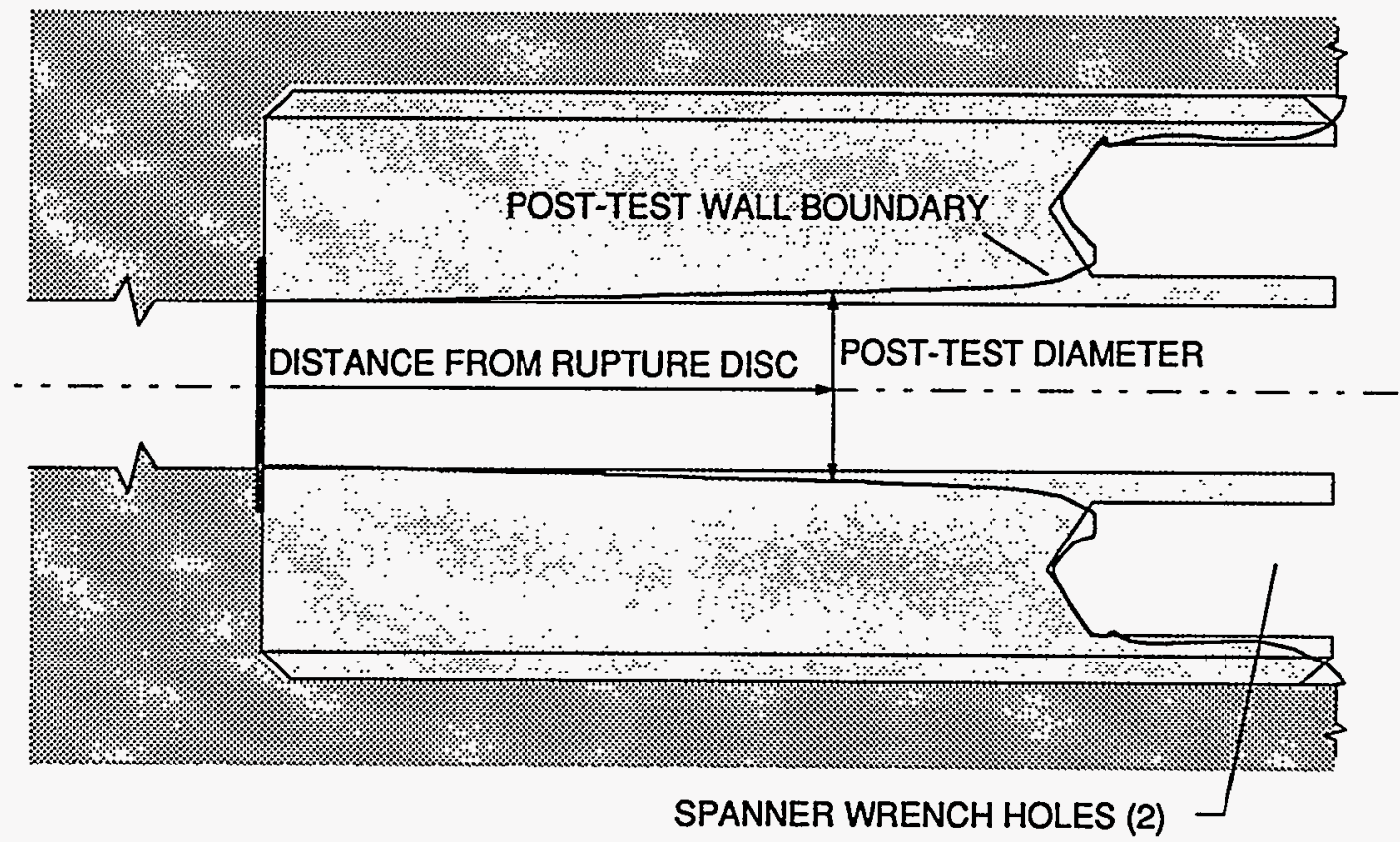

Fig. 13. Post-test examination of transition column holders.

\section{Discussion}

A previously developed, two-stage approach to achieving detonation in a secondary explosive was examined in some detail in the current study for the case of ignition by a pulsed, solid-state (rod) laser. A basic objective of this study was to gain insights into the factors that governed time scales for ignition, reaction growth, shock formation, and transition to detonation. Ignition behavior was measured in terms of an "induction time" defined by the time from the start of laser output to the initial rise of pressure to some particular value. Reaction growth was examined by recording the complete pressure history in the ignition stage up to the linear-output limit of the pressure transducer used for these measurements. Shock formation in the transition column was driven by motion of the sheared rupture disc, and experiments using inert transition materials were conducted to estimate disc shearing times. Growth-to-detonation in the transition column 


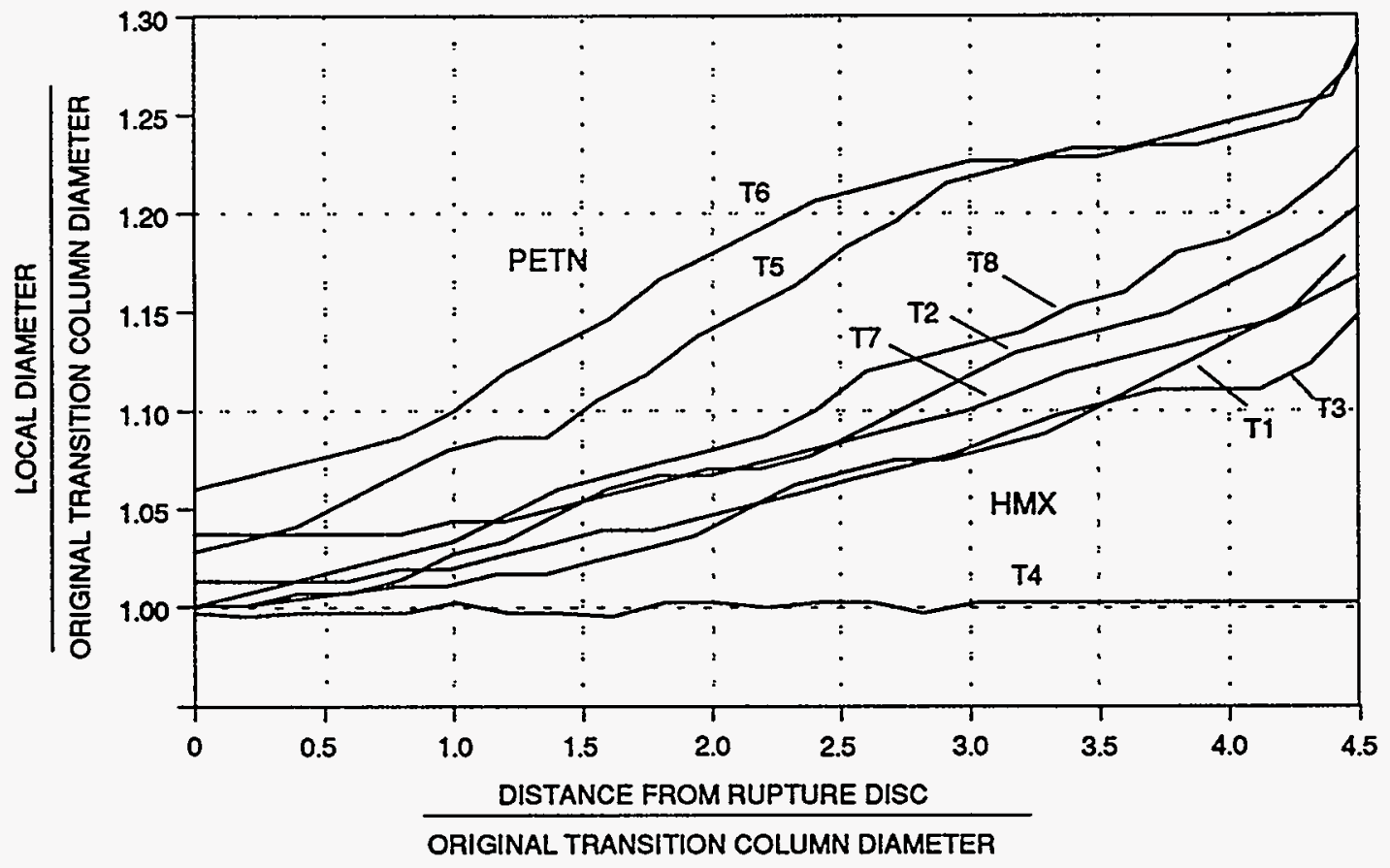

Fig. 14. Post-test diameter measurements of transition column holders.

was examined by function time measurements and by post-test measurement of the progressive diameter expansion of the transition column holder.

The "induction time" measurements summarized in Figs. 5-7 clearly showed certain trends. The shortest times were obtained with the Ti/sapphire laser, which has the highest rate of energy deposition during the initial few microseconds (but not necessarily the highest peak power). These times increased linearly with ignition column length. Experiments performed with different fiber diameters indicated that times would increase with decreasing energy/power density at the $\mathrm{HMX} /$ window interface. With column length and fiber size fixed, a correlation with initial energy deposition was suggested (Fig. 7), although the scatter in the results (Figs. 6 and 7) is quite large. Variations in these measurements under nominally constant experimental conditions could be due to differences in the absorption of the optical power by the heterogeneous HMX/graphite pressings. Laser absorption occurs directly at the window interface and also at some depth due to material porosity and optical scattering. Graphite particles absorb much more effectively than HMX at the laser wavelength, and heat transferred from the graphite to adjacent HMX grains can substantially increase the net HMX heating. Several factors suggest that this process may not have been consistent during the ignition stage experiments. Low-power measurements of the hemispherical reflectance and transmittance of similarly pressed samples of the same HMX/graphite powder demonstrated sample-to-sample differences of more than $20 \%$ in the effective absorption coefficient $^{13}$. In addition, pre-test visual examination of ignition stage pressings through the sapphire window using a microscope showed apparent differences between pressings in the areal percent of graphite and in the characteristic sizes of the graphite particles. 
However, even though the role of absorbing dopants was shown to be very important under conditions of laser diode ignition (at power densities several orders of magnitude lower than the current experiments) ${ }^{9}$, it was found to be relatively unimportant under conditions of Q-switched laser initiation (at power densities several orders of magnitude higher) ${ }^{2}$. The relative role of optical dopants at the laser powers used in the current experiments, and the possibility of better control of the particle size and blending of dopants, would be useful topics for further studies.

The growth of reaction throughout the ignition stage explosive was reflected in the total pressure histories (Fig. 8). These histories showed distinct behavior regions, although larger variability was observed in the details of these regions than in just the "induction time" data. The time required to reach the upper limit of the transducer's linear range (30 kpsi) was taken to be a measure of ignition stage "function time" (Fig. 9). The spread in these times under relatively fixed experimental conditions was 30-35 $\mu \mathrm{s}$, making trend identification difficult. An expected reduction in times with shorter column lengths was indicated, but trends based on laser characteristics were not evident. A possible reason for the variability in the total pressure histories is inconsistent sealing of the ignition charge at the window and transducer. Complete pressure confinement during reaction growth is essential for minimizing time scales. The copper seals used on these fixture elements were intended to be stressed beyond their elastic yield strength ( $>45 \mathrm{kpsi}$ ) by requiring certain torques to be applied during fixture assembly. However, a constant relationship between applied torque and seal stress is difficult to achieve in practice, and a lack of consistency in the actual sealing stresses could have resulted in premature venting of the ignition stage during the spread of reaction. Although pressures achieved by complete constant-volume reaction would ultimately cause properly stressed seals to fail, post-test examination of the fixtures showed no consistency in apparent failure mode. On most tests either the window or transducer seals would show evidence of venting, or the transducer itself would show evidence of internal failure. On many tests the window was destroyed. The results most representative of sustained constant-volume reaction are probably-those characterized by the shortest times, and even for these experiments a clear advantage for a particular laser source is not apparent. Further work on ignition stage sealing would definitely be a useful aspect of future studies.

Shock wave generation in the transition column explosive depends on the dynamic shearing of the rupture disc and its subsequent acceleration. Consequently, the composition and thickness of the rupture disc are important experimental parameters. A thicker disc should rupture at a higher pressure, sustaining the progressive constantvolume reaction in the ignition stage explosive for a longer time. Once sheared, however, the thicker disc has more mass to accelerate. A high-strength, low-density titanium alloy was first used by Ewick ${ }^{5}$ at a thickness of $0.25 \mathrm{~mm}$. The range of thicknesses used in the current experiments was based on predictions for dynamic yielding around the perimeter of the clamped disc at pressures ranging from approximately 10 to $60 \mathrm{kpsi}$. The estimates of disc failure time as a function of thickness (Fig. 11) show the expected trend, although the change with thickness is comparable to the spread of estimates for a particular thickness. The fastest estimates shown in Fig. 11 are slightly longer than the fastest 
comparable times to reach $30 \mathrm{kpsi}$ (8.0-mm column length) shown in Fig. 9, indicating that in these experiments the actual yielding was occurring after the onset of rapid pressure growth (Figs. 4 and 8) as intended. Post-test examination of these fixtures (particularly after sectioning) showed very clean shearing of the rupture discs around their perimeters, suggesting that the sheared discs were intact rather than fragmented. This suggestion is consistent with the demonstrated resistance of this titanium alloy to fragmentation under conditions of very rapid acceleration ${ }^{14}$. An intact disc accelerating into the transition column in a reasonably one-dimensional fashion is a transition-to-detonation configuration that has been studied in some detail 15 .

The complete transition experiments showed several useful trends. As expected from general shock sensitivity characteristics, a $1.16 \mathrm{~g} / \mathrm{cm}^{3} \mathrm{HMX}$ powder having relatively large particles was much more useful for achieving detonation than a $1.24 \mathrm{~g} / \mathrm{cm}^{3}$ finegrained HMX (which showed no evidence of growth towards detonation in our $16.5-\mathrm{mm}$ long transition columns). Dinegar ${ }^{7}$ tested 0.8 and $1.0 \mathrm{~g} / \mathrm{cm}^{3} \mathrm{HMX}$ in two-stage devices ignited by a hot wire, and found that only the lowest density would detonate. Ewick ${ }^{5}$ was successful in detonating 1.0 and $1.2 \mathrm{~g} / \mathrm{cm}^{3} \mathrm{HMX}$ in a two-stage device ignited by a laser diode, but observed somewhat longer function times at the higher density. Clearly, further studies would be necessary to establish an optimum grain size distribution and pressing density. Dinegar ${ }^{7}$ also examined different rupture disc materials and thicknesses, and found that detonation could only be achieved in HMX with the thinnest discs. In the present study, the fastest function times (Table 2) were obtained with the thinnest discs tested $(0.38 \mathrm{~mm})$, and a trend for longer function times with thicker discs was clear. This trend suggests that a $0.22-\mathrm{mm}$ thick rupture disc (used with other loads but not with the coarse-grained HMX) could have provided a shorter function time than was observed. In addition, the fastest function times were achieved with the both the Ti/sapphire and the $\mathrm{Nd} / \mathrm{YAG}$ lasers, indicating that the higher initial power levels of the Ti/sapphire laser may minimize "induction times" (Fig. 6) but may be less important for the overall generation of a detonation. The results observed with a Ti/sapphire laser misfire (Fig. 12) raise the question of whether laser power incident at later times $(>15 \mu \mathrm{s})$ can contribute importantly to final pressure growth in the ignition stage. Further studies could examine this question by shuttering the incident laser pulse of the Nd/YAG laser at certain times within its total pulse duration.

Post-test measurements of the transition column holder showed significant expansion in experiments that were judged to have detonated (Fig. 14). The maraging steel used in these thick-walled fixtures has a nominal compressive yield strength of $150 \mathrm{kpsi}$, although much higher values can be achieved through proper material aging. The two experiments conducted using low-density PETN were expected to show a more rapid transition (due to this material's greater shock sensitivity), and the corresponding post-test measurements showed larger diameters closer to the rupture disc than in the HMX experiments. The measurements on HMX fixtures showed a more gradual expansion with distance, consistent with a relatively slow transition process. The gross deformations in the region of the spanner wrench holes (Fig. 13) may have prevented a clear picture of the final HMX transition behavior. The expansions of the fixtures in the region of the wrench holes were 
similar for all detonating experiments, with the largest deformations measured for the slowest HMX case (T8).

In summary, the current study shows that detonations can be generated in HMX or PETN in less than $50 \mu \mathrm{s}$ in a two-stage device using pulsed (but not Q-switched) solidstate lasers. A Ti/sapphire laser gave the best overall results, but comparable function times were achieved using a simpler Nd/YAG laser. The trends established in parameter studies indicate that faster function times could possibly be obtained by reducing the ignition column length and by using a thinner rupture disc. In addition, optimization of both the doped ignition stage explosive and the transition stage explosive, together with improvements in pressure sealing of the ignition stage, could further reduce function times and minimize their variability.

\section{References}

1. L. C. Yang and V. J. Menichelli, "Laser Initiation of Insensitive High Explosives," Proceedings of the Sixth Symposium (International) on Detonation, Office of Naval Research, ACR-221, Arlington, VA, 1976, P.612. Also: references cited within.

2. D. L. Paisley, "Prompt Detonation of Secondary Explosives by Laser," Proceedings of the Ninth Symposium (International) on Detonation, Office of the Chief of Naval Research, OCNR 113291-7, Arlington, VA, 1991, p.1110.

3. A. M. Renlund, P. L. Stanton, and W. M. Trott, "Laser Initiation of Secondary Explosives," Proceedings of the Ninth Symposium (International) on Detonation, Office of the Chief of Naval Research, OCNR 113291-7, Arlington, VA, 1991, p.1118.

4. R. E. Setchell, "Damage Studies in High-Power Fiber Transmission Systems," SPIE Proc. 2114, 1994 (in press).

5. D. W. Ewick, T. M. Beckman, and D. P. Kramer, "Feasibility of a Laser-Ignited HMX Deflagration-to-Detonation Transition Device for the U. S. Navy LITES Program," EG\&G Mound Applied Technologies Report MLM-3691, 1991.

6. M. F. Folsom, Whittaker Ordnance, private communication (1992).

7. R. H. Dinegar, "The Deflagration-to-Detonation Transition in PETN and HMX," Los Alamos National Laboratory Report LA-9620 (1983).

8. D. W. Ewick, "Development of a PETN DDT Detonator," Proceedings of the Ninth International Pyrotechnics Seminar, IIT Research Institute, Chicago, IL, 1984, p.143. 
9. D. W. Ewick, T. M. Beckman, J. A. Holy, and R. Thorpe, "Ignition of HMX Using Low Energy Laser Diodes," Proceedings of the Fourteenth Symposium on Explosives and Pyrotechnics, Franklin Applied Physics, Inc., Oaks, PA, 1990, p.2-1.

10. LASL Shock Hugoniot_Data, S. P. Marsh, Ed., University of California Press, Berkeley, 1980, p. 332.

11. J. W. Fronabarger, "Final Report on the Preparation of Blends of Carbon with HMX, RDX, and BNCP for Laser Sensitivity Studies," Unidynamics/Phoenix Report MTR-336 (1991).

12. J. A. Merson, Sandia National Laboratories, private communication.

13. W. M. Trott, Sandia National Laboratories, to be published.

14. L. C. Chhabildas, L. M. Barker, J. R. Asay, and T. G. Trucano, "Relationship of Fragment Size to Normalized Spall Strength for Materials, J. of Impact Engineering 10, 107 (1990).

15. J. M. McAfee, B. W. Asay, A. W. Campbell, and J. B. Ramsay, "Deflagration to Detonation in Granular HMX," Proceedings of the Ninth Symposium (International) on Detonation, Office of the Chief of Naval Research, OCNR 113291-7, Arlington, VA, 1991, p.265. 


\section{APPENDIX \\ Required Reportable Information \\ Lab Directed Research and Development}

FY93 LDRD Project "Fast Optical Deflagration-to-Detonation (DDT) Detonators"

\section{Publications and presentations:}

R. E. Setchell and W. M. Trott, "Prompt Laser Ignition and Transition to Detonation in a Secondary Explosive," in Proceedings of the Fifteenth Symposium on Explosives and Pyrotechnics, Franklin Applied Physics, Philadelphia, 1994, p. 6-1.

(Symposium presentation: April 19, 1994, Philadelphia)

Invention disclosures: none

Patents: none

Copyrights: none

Employee recruitment: none

Student involvement: none 


\section{DISTRIBUTION:}

4 Los Alamos National Laboratory

Attn: P915 J. E. Kennedy, DX-DO

P950 J. M. McAfee, DX-10

P950 J. J. Dick, DX-10

P952 S. Sheffield, DX-10

PO Box 1663

Los Alamos, NM 87545

2 Lawrence Livermore National Laboratory

Attn: L-281 R. S. Lee

L-281 A. M. Frank

PO Box 808

Livermore, CA 94550

1 MS 1436 D. L. Chavez, 1011

10834 A. C. Ratzel, 1512

10834 M. R. Baer, 1512

50834 W. M. Trott, 1512

10985 M. W. Callahan, 2604

10985 D. E. Mitchell, 2607

10329 J. G. Harlan, 2652

10329 J. A. Merson, 2652

10326 F. H. Braaten, Jr., 2653

10327 L. L. Bonzon, 2654

10327 A. M. Renlund, 2654

10328 J. A. Wilder, 2674

10429 W. C. Nickell, 5100

10445 R. C. Hartwig, 5166

$10 \quad 0445$ R. E. Setchell, 5166

10445 K. D. Meeks, 5166

19054 W. J. McLean, 8300

19055 F. P. Tully, 8353

11156 P. W. Cooper, 9333

19052 D. R. Hardesty, 8361

19018 Central Technical Files, 8523-2

50899 Technical Library, 13414

10619 Print Media, 12615

20100 Document Processing, 7613-2

For DOE/OSTI 